Ethnic Identity as a Protective Factor in the Lives of Asian American Adolescents

By: Gabriela L. Stein, Lisa Kiang, Andrew J. Supple, Laura M. Gonzalez

Stein, G.L., Supple, A.J., Kiang, L., \& Gonzalez, L.M. (2014). Ethnic Identity as a protective factor in the lives of Asian American adolescents. Asian American Journal of Psychology. doi:.1037/a0034811

Made available courtesy of American Psychological Association: http://psycnet.apa.org/doi/10.1037/a0034811

**This article may not exactly replicate the final version published in the APA journal. It is not the copy of record.**

\begin{abstract}
:
This study examined the buffering role of ethnic identity for Asian American adolescents living in an emerging immigrant community. A sample of 176 Asian American ninth graders completed self-report measures assessing ethnic identity, stressors (i.e., perceived racial/ethnic discrimination; economic stress), and mental health outcomes (i.e., depressive symptoms, selfesteem) at two time points a year apart. The study tested whether ethnic identity moderated the relationships between discrimination and economic stress and mental health outcomes. Ethnic identity did not buffer or exacerbate the relationship between discrimination and mental health outcomes, and discrimination was a consistent predictor of concurrent functioning. However, ethnic identity served both to buffer and to exacerbate in predicting mental health outcomes when youth reported high levels of economic stress. These findings suggest that it is important to further examine the role of ethnic identity for youth facing high levels of economic stress, especially in emerging immigrant communities.
\end{abstract}

Keywords: Ethnic identity | Discrimination | Economic stress | Depressive symptoms | Adolescents

\title{
Article:
}

Ethnic identity may play a key role in protecting Asian American adolescents from typical stressors associated with being an ethnic minority adolescent. To date, however, the few available studies which directly test such an assertion have yielded inconsistent results. Although some studies suggest that ethnic identity may serve to shield Asian American youth from deleterious outcomes when confronted with racial/ethnic discrimination (e.g., Rivas-Drake, Hughes \& Way, 2008), other studies find that ethnic identity can serve to exacerbate these negative experiences, leading to worsened mental health outcomes (e.g., R. M. Lee, 2005). In addition to inconsistent findings, the majority of ethnic identity research studies use samples living in established Asian American communities or samples of college students. As a result, it is unclear if ethnic identity is a protective factor among Asian American adolescents in emerging immigrant communities where other residents (non-Asians) have little familiarity with Asians. This article addresses these limitations by (a) examining whether ethnic identity buffers potentially deleterious associations between experiences of ethnic/racial discrimination and 
economic stress and psychological well-being; and (b) studying Asian American adolescents living in an emerging immigrant community.

\section{Ethnic Identity}

Although there are multiple models of ethnic identity, most studies focus on Phinney's model, which conceptualizes ethnic identity as primarily comprised of a sense of belonging to and exploration of one's ethnicity (Phinney, 1992). A sense of belonging describes an adolescent's sense of personal investment and attachment to their ethnic group. It may include individual feelings (e.g., pride in being Chinese American) and also a sense of connection to the group (Phinney \& Ong, 2007a). Exploration involves seeking information, participating in cultural activities, and learning about the ethnic group's history, values, attitudes, and cultural artifacts and traditions. In adolescence, these two aspects of ethnic identity appear to be the most salient and they continue to develop as young people move from childhood through adolescence and into young adulthood (French, Seidman, \& LaRue, 2006; Phinney \& Ong, 2007a). Studies have found that a stronger ethnic identity (i.e., higher exploration and belonging) is associated with improved functioning among Asian American adolescents, including greater self-esteem, decreased depressive symptoms, and better academic outcomes (e.g., Fuligni, Witkow, \& Garcia, 2005; Iwamoto \& Liu, 2010; Phinney \& Ong, 2007b; Yip, 2005).

In addition to direct associations of ethnic identity with improved outcomes, social identity theory (Tajfel \& Forbas, 2000) suggests a moderating mechanism. A strong sense of ethnic identity may protect ethnic minority individuals by letting them focus on positive aspects of their group membership when confronted with ethnic/racial discrimination. Furthermore, the protective effect of ethnic identity may extend to other types of stressors by providing Asian American adolescents with a sense of social connectedness, a positive sense of self, and a sense of purpose that can serve as psychological resources to youth when facing stressful life events (Costigan, Koryzma, Hua, \& Chance, 2010; Kiang, Yip, Gonzales-Backen, Witkow, \& Fuligni, 2006; Shelton et al., 2005). Theoretically, one's sense of belonging to a group is the critical component of ethnic identity that would confer this protective effect. However, studies in other ethnic groups have documented that other aspects of ethnic identity are also beneficial. For example, greater ethnic exploration in Navajo youth protected them against substance use when facing ethnic/racial discrimination (Galliher, Jones, \& Dahl, 2011). One reason that ethnic exploration may serve this protective role is that it might promote spending time in structured activities with members of one's ethnic group, thus accessing social support and building feelings of solidarity. However, in emerging immigrant areas without a large coethnic community, ethnic exploration and belonging may operate differently and involve a different set of activities than what has been reflected in the existing literature based on established immigrant areas (Rumbaut, 1994).

\section{The Context of Emerging Immigrant Communities}


There have been few studies examining the psychosocial health of Asian American adolescents who reside in communities where Asian Americans are quickly increasing in number yet still make up a small portion of the larger population (e.g., North Carolina) (e.g., Schwartz, Zamboanga, \& Jarvis, 2007). Compared to more traditional areas of migration, emerging immigrant communities are characterized by fewer ethnic enclaves, a poorer network of support, less ethnic/racial diversity, and a less experienced immigrant community (Stamps \& Bohon, 2006). In such a context, ethnic identity may play a unique and qualitatively different role. Ethnic exploration or belonging may exert stronger or weaker protective roles for adolescents who reside in areas where there are fewer ethnic minorities overall and, in particular, smaller percentages of Asian Americans.

Previous research, while limited, has suggested that the broader cultural and ethnic context can impact the development and salience of ethnic identity. For example, a study of Asian and Latino college students suggested no relationship between ethnic belonging and self-esteem for youths living in California, but an association of greater ethnic belonging with greater self-esteem for youth living in the Midwest (Umaña-Taylor \& Shin, 2007). Such a finding raises the possibility that the salience of ethnic identity may be greater for adolescents in emerging immigrant communities. However, in contrast to these results, another study of Asian American university students found that ethnic identity was related to positive adjustment (i.e., less depressive symptoms) more so for those in a setting with a larger portion of Asian Americans than those in a setting with few Asian Americans (Juang, Nyugen, \& Lin, 2006). Thus, it may also be that ethnic identity is not as relevant for Asian American adolescents in emerging immigrant contexts, who might tend to underplay their ethnicity to be accepted by the larger majority group. These conflicting results suggest that further research is needed to explicate the role of ethnic identity for these understudied youth.

In terms of protective effects, a high level of ethnic belonging and exploration may play an even greater role buffering the effects of negative experiences such as ethnic/racial discrimination and economic stress for Asian American youth living in emerging immigrant communities. Research suggests that these youth may experience multiple types of racial/ethnic discrimination (e.g., model minority, deviance, feeling ignored) and that economic strain is salient for these families as well (S. J. Lee, 2001; Supple, McCoy, \& Wang, 2010). In these contexts, ethnic identity may represent a particularly meaningful resource. If Asian American youth lack the cultural network that provides guidance and support in adjusting to a foreign environment (Lueck \& Wilson, 2010), they may need to rely more heavily on their own coping resources to effectively deal with ethnic/racial discrimination and economic stress.

\section{Ethnic/Racial Discrimination}

Ethnic/racial discrimination poses a serious risk to Asian American youth. Studies suggest that a significant portion of Asian American adolescents report being taunted by peers, excluded and rejected, treated as a perpetual foreigner, and being targets of mistreatment due to their 
race/ethnicity (Benner \& Kim, 2009; Rosenbloom \& Way, 2004). Although ethnic and racial discrimination are distinct (the former refers to discrimination due to one's belonging to an ethnic group and the latter refers to discrimination in a larger sociopolitical context of oppression), these distinctions are not always captured in the current measures used with adolescents and thus we use the term ethnic/racial discrimination. Studies have found that Asian American youth are exposed to the greatest peer discrimination compared to African Americans and Latinos (i.e., Greene, Way, \& Pahl, 2006). Ethnic/racial discrimination predicts worse psychosocial (e.g., self-esteem, depressive symptoms) and academic outcomes (e.g., grades, school connection) concurrently and longitudinally (Benner \& Kim, 2009; Greene et al., 2006; Grossman \& Liang, 2008; Juang \& Cookston, 2009; Rivas-Drake et al., 2008). In the face of these negative effects, researchers have sought to uncover attenuating factors, with some arguing that ethnic identity may be a particularly promising protective resource. From a social identity perspective (Tajfel \& Forbas, 2000), adolescents may be somewhat protected from discrimination when they have a strong sense of connection to and pride in their group and are familiar with their group’s cultural assets.

The majority of studies conducted with Asian American adolescents do find that ethnic identity serves a protective role against experiences of discrimination. These handful of studies have found that those with higher levels of ethnic identity (particularly ethnic belonging) report better psychological functioning than those with low levels of ethnic identity when facing racial/ethnic discrimination (e.g., Greene et al., 2006; Rivas-Drake et al., 2008; Shelton et al., 2005). Yet, these studies are limited in that they have been conducted in settings where Asian Americans constitute a significant portion of the populations (e.g., New York City, Los Angeles) (Greene et al., 2006; Kiang et al., 2006; Rivas-Drake et al., 2008). It remains to be tested whether ethnic identity provides this same buffer in an emerging immigrant community.

Notably, the protective effect of ethnic identity for Asian Americans facing discrimination has not been consistent, especially when considering college student samples consisting of older adolescents and young adults. Many studies that have been conducted in college-aged samples have failed to find a protective effect of ethnic identity (e.g., Iwamoto \& Liu, 2010; R. M. Lee, 2003; Pascoe \& Smart-Richman, 2009). For example, among college students, R. M. Lee (2005) found that high ethnic identity or ethnic achievement is only protective at low levels of ethnic/ racial discrimination. Thus, it appears that the relationship among ethnic identity, discrimination, and psychosocial outcomes is very complex and may depend on additional factors such as ethnic context and individuals' developmental stage. The present study attempts to build on our understanding and be the first to address these understudied issues by examining the moderating role of ethnic identity among an adolescent sample in an emerging community.

\section{Economic Stress}

In addition to discrimination, Asian Americans also contend with other stressors. The "model minority myth” portrays Asian Americans as successful in many ways (Oyserman \& Sakamoto, 
1997). This myth obscures the fact that although some Asian Americans have obtained material success, there are many Asian Americans who struggle financially, especially recently immigrated families (De Castro, Gee, \& Takeuchi, 2010). According to the U.S. Census, 12\% of American and Pacific Islander households are below the poverty line, similar to the rate in nonHispanic Whites (U.S. Census, 2009). Moreover, the median household income for an Asian immigrant family is only $\$ 49,800$ compared to the average Asian American household whose income is \$66,000 (Pew Research Center, 2012). Because material and economic success is part of the "model minority myth," Asian American adolescents living in families with high levels of economic stress may therefore be particularly vulnerable to depressive symptoms and low selfesteem. Although few studies have examined the psychological effects of economic stress in Asian American adolescents, a recent study found that their perception of economic stress was directly related to depressive symptoms (Mistry, Benner, Tan, \& Kim, 2009). Similarly, the link between perceived economic stress and depressive symptoms was found in a diverse sample of Asian American college students (Ishii-Kuntz, Gomel, Tinsley, \& Parke, 2010).

Past studies have not considered the potentially protective role of ethnic identity in response to economic stress in Asian American adolescents. When faced with economic stress, a strong sense of ethnic identity may help youth place their difficulties in the context of the struggle of other youth similar to themselves. It may help them to appreciate their parents' sacrifices in immigrating to the United States and to understand that, despite their family's economic struggles, improved outcomes may result for the family. The contextualizing of their economic stress may result in a sense of camaraderie and connection that may help them cope. In addition, a strong sense of ethnic identity may help youth access social support, as they may have other peers going through similar situations (Costigan et al., 2010). Yet, whether ethnic identity buffers youth outcomes in the face of economic stress remains an empirical question.

Furthermore, the majority of the research examining the moderating role of ethnic identity has examined these relationships concurrently or over a short-time period (e.g., Rivas-Drake et al., 2008; R. M. Lee, 2003, 2005). Thus, how ethnic identity protects youth over time is not wellunderstood. Although a strong ethnic identity may operate as a protective mechanism only at the time the youth is exposed to stress as it facilitates adaptive coping, some evidence also suggests that ethnic identity may confer its benefits longitudinally. In fact, experiences of ethnic/racial discrimination may actually promote or further develop ethnic identity in adolescence. A recent study examined this question with Latino youth and found that exposure to discrimination actually strengthened identity and cultural values and thereby provided protective effects for youth (Berkel et al., 2010). More recent studies that examine associations among ethnic identity, stress, and outcomes over time are therefore important to further our understanding.

\section{The Current Study}

Given the review above, this study of adolescents in an emerging immigrant community hypothesized that (a) stronger ethnic identity (belonging and exploration) would be related to 
improved psychosocial outcomes (self-esteem and depression) for Asian American adolescents concurrently and longitudinally; (b) greater discrimination and economic stress would be associated with poorer psychosocial outcomes for Asian American adolescents both concurrently and longitudinally; and (c) a stronger ethnic identity (belonging and exploration) would buffer against the negative psychosocial effects of discrimination and economic stress on outcomes both concurrently and longitudinally.

\section{Method}

\section{Participants}

Participants at Time 1 included 176 ninth and tenth graders (50\% of each) recruited from six public high schools in an emerging immigrant community in the southeastern United States. A stratified cluster design was used to select high schools for recruitment, based on their relatively larger proportion of Asian students (4-6\%). Schools were diverse in overall ethnic/racial composition, socioeconomic status, and academic achievement. The average age was 14.97 years ( $S D_{-} .84$ ) and $42 \%$ of the respondents were male. Students were identified as pan-ethnically Asian according to school enrollment forms. More specifically, adolescents represented several self-reported ethnic groups: 28\% Hmong, 22\% multiethnic Asian (e.g., Cambodian and Chinese), 11\% South Asian, 8\% Chinese, 8\% pan-ethnic (e.g., Asian), and 23\% were small clusters from Montagnard, Laotian, Vietnamese, Filipino/a, Cambodian, Japanese, Korean, or Thai backgrounds. Adolescents were primarily of the second-generation with at least one foreign-born parent (75\%). The remaining 25\% were first generation. Of the first-generation adolescents, the average age of immigration was $7.03\left(S D_{-}\right.$5.03). All adolescents were invited to complete a follow-up study 1 year later. Of the original 176, approximately 93\% ( $\left.n_{-} 163\right)$ participated at Time 2. Rates of participation in T2 did not vary by gender, age, ethnicity, or generational status.

\section{Procedures}

In small groups at school (e.g., in the library), students were invited to participate in a study on their cultural identity, social relationships, and daily lives. Approximately $60 \%$ of students returned parental consent and assent forms during a follow-up visit, received a packet of questionnaires, and completed the packet in approximately 30-45 min. As part of the larger study, students were also given materials to complete 14 daily diaries, which asked about their daily experiences and emotions (e.g., Were you late for school?, Did you argue with a friend?). The current study uses only data from the questionnaire packets. At the end of the 2-week study period, students retuned all materials and were given a gift card to a retail store.

Procedures were similar at T2. Adolescents who participated in the first wave were reconvened in small groups at school and provided with a brief description of the study. Students then completed nearly identical questionnaires and were given a gift card to a retail store. Responses from T1 and T2 were linked through ID numbers that were assigned to participants. Daily diaries 
were not completed at T2. Students who were absent or no longer enrolled at school were mailed questionnaires using contact information collected at T1.

\section{Measures}

Depressive symptoms. The Center for Epidemiologic Studies-Depression Scale (CESD-10; Andresen, Malmgren, Carter, \& Patrick, 1994) was used to measure symptoms of depression. Adolescents were asked to rate on a 4-point scale ranging from 0 (rarely or none of the time) to 3 (all of the time) the extent to which they experienced depressive symptoms within the previous week. The internal consistency was .72 at T1 and .76 at T2. The CESD has been used extensively with Asian American youth (e.g.,Benner \& Kim, 2009; Juang \& Cookston, 2009).

Self-esteem. The Rosenberg Self-Esteem Scale (RSES; Rosenberg, 1989) consists of 10 Likertscale items designed to assess positive evaluations of the self. Respondents indicate their level of agreement ranging from 1 (strongly disagree) to 4 (strongly agree). Five of the items indicate greater self-esteem (e.g., "I feel that I have a number of good qualities”), and five indicate lower self-esteem (e.g., "I certainly feel useless at times”). Negatively worded items were reverse coded, then all items were averaged to create a summary score. Cronbach's alpha for the RSES in this sample was .76 at T1 and .84 at T2. The scale also been used extensively with Asian American youth (e.g., Rivas-Drake et al., 2008; Kiang et al., 2006).

Ethnic identity. Two subscales of the Multigroup Ethnic Identity Measure (Phinney, 1992) assessed ethnic identity. The Affirmation and Belonging subscale consists of five items, and assesses ethnic pride, feeling good and happy about one's ethnic background, and feelings of belonging and attachment to one's ethnic group. The Exploration subscale consists of seven items and measures individuals' exploration and active efforts to learn more about their ethnic group. All items are scored on a 5-point scale ranging from 1 (strongly disagree) to 5 (strongly agree) with higher scores reflecting higher Belonging and higher Exploration. Internal consistencies were .75 for Exploration and .93 for Belonging at T1.

Perceived racial/ethnic discrimination. To measure perceived racial/ethnic discrimination, adolescents were asked, "How often have you felt racial or ethnicity-based discrimination in the following situations?” in reference to a list of seven items (e.g., being treated unfairly, being treated with less respect, being feared, being disliked, being insulted or called names, being threatened or harassed, and not being trusted). On a 5-point scale ranging from 1 (never) to 5 (all the time), respondents indicated the frequency of each of the seven events $\left(\mathrm{M}_{-} 1_{.68} S D_{-} .74\right)$. This measure was developed for use with multiple ethnic groups (Greene et al., 2006) and was based on extensive qualitative research (Rosenbloom \& Way, 2004). The internal consistency was .89 at T1.

Economic stress. On a $0=$ no to $1=$ yes scale, adolescents were asked to indicate whether their families experienced economic stressors. There were five items (e.g., were without home telephone service or cell phone service because there was not enough money, did not pay the full 
amount of rent or mortgage because there was not enough money, were worried whether food would run out before there was more money to buy more, were evicted from your house or apartment, had service turned off by the gas or electric company). Adolescents were instructed to think about the past 12 months in their responses. This measure has been used in prior work with immigrant youth (e.g., Brumbach, Figueredo, \& Ellis, 2009) and the internal consistency found in the current study was acceptable (T1 $\alpha=.63)$.

\section{Results}

Correlations among the primary study variables and descriptive statistics (means and standard deviations) are shown in Table 1. Ethnic exploration was significantly correlated with higher self- esteem at T1 and both higher self-esteem and lower depressive symptoms at T2. Ethnic belonging was significantly related to both higher self-esteem and lower depressive symptoms at T1, but only higher self-esteem at T2. Higher levels of perceived racial/ethnic discrimination and economic stress were significantly correlated with more depressive symptoms and lower selfesteem at both time points.

[Table 1 Omitted]

In addition, preliminary analyses examined gender, grade, and generational status as possible confounding variables. One significant gender difference was found, $t(170)=2.45, p<.05$ whereby females reported higher levels of ethnic exploration compared to males. No other gender differences were found ( $t$ range $=.24-1.35, n s$ ). Variable means were not found to vary by grade orgenerational status ( $t$ range $=.00-1.69, n s)$.

A series of hierarchical regressions were estimated to examine main and interactive effects of ethnic/racial discrimination and economic stress and ethnic identity on (a) depressive symptoms at T1, (b) depressive symptoms at T2, (c) self-esteem at T1, and (d) self-esteem at T2. Given preliminary analyses described above, adolescent gender was entered in the first step as a covariate along with racial/ethnic discrimination and economic stress and the two indicators of ethnic identity. For T2 outcomes, depressive symptoms or self-esteem measured at T1 were also entered in the first step of the regression models.

To test Hypotheses 1 and 2, we examined the main effect models predicting the two outcomes at both time points. Ethnic belonging was not significantly related to depressive symptoms at either time point (see Table 2) but was related to greater self-esteem only at T1. Ethnic exploration significantly predicted fewer depressive symptoms at T2 and greater self-esteem at T1 and T2. Ethnic/racial discrimination predicted more depressive symptoms and lower self-esteem only at T1. Economic stress was only related to lower self-esteem at T1. These models accounted for $21 \%$ and $34 \%$ of the variance in depressive symptoms and self-esteem, respectively, at T1, corresponding to moderate to large $f 2$ effect sizes of .27 and .58 (Aiken \& West, 1991). 
To examine the protective effect of exploration and belonging, interaction terms were created as the product between each indicator of ethnic identity and each outcome (e.g., exploration by ethnic/racial discrimination). We entered these interaction terms in the next step of the model. As suggested by Aiken and West (1991), the ethnic identity, ethnic/racial discrimination, and economic stress variables were centered prior to being entered in the models.

In terms of depressive symptoms, there were no significant interactions at $\mathrm{T} 1$, but there was a significant interaction with ethnic belonging and economic stress at T2 (see Table 2). To further probe this interaction effect we used the online calculation utility created by Preacher, Curran, and Bauer (2006). Simple slope values were calculated by treating belonging as the moderator variable and quantifying greater levels of belonging as $1 S D$ above the mean and less belonging as $1 S D$ below the mean. Only the simple slope for greater levels of belonging was significant (B $=.276, p=.01$ ), and the simple slope for low levels of belonging was only trend-level significant ( $\mathrm{B}=-.186, p=.07$ ) (see Figure 1a). This interaction suggests an exacerbating effect such that economic stress at T1 was associated with greater depressive symptoms at T2 only for those with high levels of ethnic belonging at $\mathrm{T} 1$. The inclusion of interaction terms predicting $\mathrm{T} 2$ depression yielded an overall increase in explained variance of $3 \%$ and an effect size of $f^{2}=.05$ which is a small effect (Aiken \& West, 1991).

[Table 2 Omitted]

In terms of self-esteem, there were two significant interactions suggesting that both ethnic belonging and ethnic exploration moderated the effect of economic stress on self-esteem at T1 (see Table 2). We probed the interaction between belonging and economic stress and found significant simple slopes at low levels of belonging $(\mathrm{B}=-.485, p<.001)$ such that greater economic stress was associated with lower self-esteem for those with low levels of ethnic belonging. Thus, ethnic belonging buffered the negative effect of economic stress on self-esteem (see Figure 1B). We probed the interaction between exploration and economic stress and found significant slopes only for those with high levels of exploration $(\mathrm{B}=-.731, p<.001)$ such that high levels of exploration exacerbated economic stress and was associated with lower selfesteem (see Figure 2). The additional interaction terms in this model added 6\% of explained variance above Model 1 , which represents a small to moderate effect $\left(f^{2}=.09\right.$; Aiken \& West, 1991). There were no significant interactions at $\mathrm{T} 2$. The interaction models accounted for $24-$ $37 \%$ of the variance in the outcomes $\left(f^{2}=.31\right.$ to .58 which represent moderate to large effect sizes).

[Figure 1 Omitted]

\section{Discussion}

The results of the current study suggest a complicated role of ethnic identity in the lives of Asian American adolescents in emerging communities. As with some past studies, ethnic identity did not serve to protect Asian American youth against ethnic/racial discrimination, and ethnic 
exploration served as a risk for Asian American adolescents under economic stress. Overall, ethnic identity, economic stress, and ethnic/racial discrimination explained about $25 \%$ of the variance in the outcomes of interest, suggesting that these variables are critical to the psychosocial well-being of Asian American youth in emerging immigrant communities.

The first hypothesis was only partially supported as ethnic belonging was related concurrently but not longitudinally to self-esteem and was unrelated to depressive symptoms. On the other hand, ethnic exploration predicted both outcomes longitudinally. These findings suggest that in an emerging community ethnic exploration is particularly beneficial in the long run, and may be more important than ethnic belonging in terms of promoting positive youth outcomes.

Our second hypothesis was also partially supported. Asian American adolescents reporting greater economic stress and ethnic/racial discrimination also reported worse psychological functioning, but only concurrently. This finding suggests that changes in either depressive symptoms or self-esteem are not due to past experiences of ethnic/racial discrimination or economic stress. This is consistent with other findings in the literature that show that for Asian American youth ethnic/racial discrimination predicted current psychological functioning but not longitudinally (Benner \& Kim, 2009). Although discrimination or family economic strain might represent chronic stress experiences for some individuals, it seems that these negative circumstances are particularly influential at a more proximal level. Recent research has indeed incorporated and emphasized the use of daily diary approaches to examine short-term effects of experiences such as discrimination (Huynh \& Fuligni, 2010), and perhaps our lack of sustained effects is due to resiliency or other protective factors (e.g., ethnic identity) that come into play over time. To understand these longitudinal relationships between ethnic/racial discrimination, economic stress, and psychological outcomes, it may be necessary to include changes in the perception of ethnic/racial discrimination and economic stress (Juang \& Cookston, 2009). Such investigations might be especially important to consider among emerging immigrant communities in which the social reception and overall characteristics of these contexts might still be in flux. Another explanation is that the strong stability in self-esteem and depression simply trumped any long-term effects of identity or discrimination in our models.

\section{[Figure 2 Omitted]}

We found partial support for the hypothesis that ethnic identity would buffer negative associations between discrimination and economic stress and the outcomes. Specifically, Asian American adolescents who feel strongly connected to their ethnic group reported greater selfesteem when facing economic stress than youth with low levels of belonging, which was consistent with past studies of daily experiences of stress (e.g., Kiang et al., 2006). The protective effect of belonging did not extend longitudinally for youth experiencing high levels of economic stress. In fact, this moderation was not significant for predicting T2 self-esteem; conversely, it predicted increases in depressive symptoms at T2 such that youth with high levels of belonging who also experienced high levels of economic stress reported increases in their 
depressive symptoms. This finding underscores the need to examine the role of ethnic identity longitudinally given that the interaction between economic stress and ethnic identity may differentially impact depressive symptoms depending on the age of the participant. It may be that youth come to view their economic stress as being linked to their ethnic identity and thus may feel trapped in poverty, leading to greater depressive symptoms. This has been suggested as a mechanism for depression in African American youth (Hammack, 2003), and a similar mechanism may be at play for Asian American adolescents. Further longitudinal work should examine how Asian American adolescents construe their economic stress, especially how it may related to their view of their ethnic group.

Although ethnic exploration appeared to be related to positive outcomes overall, higher levels of exploration exacerbated the experiences of economic stress on self-esteem at $\mathrm{T} 1$, such that youth who had greater exploration and economic stress reported lower self-esteem. This stands in contrast to the protective effect of ethnic belonging for economic stress and self-esteem. These seemingly contradictory findings may be explained by the potential financial costs of ethnic exploration. Unlike ethnic belonging, exploration may necessitate economic means; to actively learn about one's cultural group, one may need to attend classes or travel or spend time with peers doing activities that cost money (e.g., joining a ethnic dance troupe, taking language classes, learning to play an ethnic instrument). In addition, given that this is a concurrent relationship, it may be that youth with low self-esteem and high levels of economic stress engage in ethnic exploration as an attempt to increase their self-esteem. This is supported by the fact that ethnic exploration led to increases in self-esteem at T2. Finally, the development of ethnic identity typically starts with exploration and ends with ethnic belonging and perhaps this finding indicates that those with a more fragile and emerging identity are more sensitive to economic stressors than those with a more firmly established ethnic identity.

Given the plethora of research on ethnic identity and ethnic/ racial discrimination, it was surprising that ethnic identity did not moderate any relationship with discrimination. This finding suggests that, for youth in an emerging community, experiences with discrimination are detrimental in terms of self-esteem and depressive symptoms regardless of their level of ethnic identification. Although we did have a small sample size that may have underpowered some of the interactions, even the interaction that was at the trend level of significance did not show a protective effect. An additional explanation for this finding may be that racial identity, and not ethnic identity, serves to buffer against ethnic/racial discrimination. Youth in these communities are likely in a small minority and their understanding of the role of systemic oppression and mistreatment in relation to race may impact their experiences of discrimination. Youth in these contexts may want to fit in to the larger majority, as they don't have the ethnic enclave to provide them with support. They also may be inundated with negative messages about their group without the counter messages that would be found in an ethnic enclave. As such, youth with less developed racial identity would be at greater risk when experiencing discrimination as has been found in past studies of Asian American college students (Iwamoto \& Liu, 2010). 
Although this study provides important additional information about ethnic identity in Asian American adolescents, there are several limitations to the conclusions that can be drawn. The sample included different nationalities which makes it difficult to ascertain whether ethnic identity serves a different function for specific ethnic groups. Although this might not differ by nationality, South Asians and East Asians may have different experiences of economic stress and discrimination.

Despite its limitations, this article has strengths that make it a unique contribution to the literature. This is the first study that examines the question of ethnic identity as a buffer in an emerging immigrant community with Asian American adolescents. The findings underscore the importance of ethnic exploration for youth in emerging contexts. Moreover, the results demonstrate that ethnic identity interacts with economic stress in predicting outcomes, and future studies should continue to examine the intersection of ethnic identity and economic stress in Asian American adolescents. This article also highlights the need for additional research to define under what conditions ethnic identity confers a protective effect for Asian American adolescents and which psychological outcomes are most affected by it.

\section{References}

Aiken, L. S., \& West, S. G. (1991). Multiple regression: Testing and interpreting interactions. Thousand Oaks, CA: Sage Publications.

Andresen, E. M., Malmgren, J. A., Carter, W. B., \& Patrick, D. L. (1994).Screening for depression in well older adults: Evaluation of a short form of the CES-D. American Journal of Preventive Medicine, 10, 77-84.

Benner, A. D., \& Kim, S. Y. (2009). Intergenerational experiences of discrimination in Chinese American families: Influences of socialization and stress. Journal of Marriage and Family, 71, 862-877.

Berkel, C., Knight, G. P., Zeiders, K. H., Jenn-Yun, T., Roosa, M. W., Gonzales, N. A., \& Saenz, D. (2010). Discrimination and adjustment for Mexican American adolescents: A prospective examination of the benefits of culturally related values. Journal of Research on Adolescence, 20, 893-915.

Brumbach, B. H., Figueredo, A. J., \& Ellis, B. J. (2009). Effects of harsh and unpredictable environments in adolescence on development of life history strategies: A longitudinal test of an evolutionary model. Human Nature, 20, 25-51.

Costigan, C. L., Koryzma, C. M., Hua, J. M., \& Chance, L. J. (2010). Ethnic identity, achievement, and psychological adjustment: Examining risk and resilience among youth from immigrant Chinese families in Canada. Cultural Diversity \& Ethnic Minority Psychology, 16, 264-273. 
De Castro, A. B., Gee, G. C., \& Takeuchi, D. T. (2010). Examining alternative measures of social disadvantage among Asian Americans: The relevance of economic opportunity, subjective social status, and financial strain for health. Journal of Immigrant and Minority Health, 12(5), 659-671.

French, S. E., Seidman, E. A., \& LaRue Aber, J. L. (2006). The development of ethnic identity during adolescence. Developmental Psychology, 42, 1-10.

Fuligni, A. J., Witkow, M., \& Garcia, C. (2005). Ethnic identity and the academic adjustment of adolescents from Mexican, Chinese, and European backgrounds. Developmental Psychology, 41, 799-811.

Galliher, R. V., Jones, M. D., \& Dahl, A. (2011). Concurrent and longitudinal effects of ethnic identity and experiences of discrimination on psychosocial adjustment of Navajo adolescents. Developmental Psychology, 47, 509-526.

Greene, M. L., Way, N., \& Pahl, K. (2006). Trajectories of perceived adult and peer discrimination among Black, Latino, and Asian American adolescents: Patterns and psychological correlates. Developmental Psychology, 42, 218-238.

Grossman, J. M., \& Liang, B. (2008). Discrimination distress among Chinese American adolescents. Journal of Youth And Adolescence, 37, 1-11.

Hammack, P. L. (2003). Towards a unified theory of depression among urban African American youth: Integrating socioecological, cognitive, family stress, and biopsychosocial perspectives. Journal of Black Psychology, 29, 187-209.

Huynh, V., \& Fuligni, A. J. (2010). Discrimination hurts: The academic, psychological, and physical well being of adolescents. Journal of Research on Adolescence, 20, 916-941.

Ishii-Kuntz, M., Gomel, J. N., Tinsley, B. J., \& Parke, R. D. (2010). Economic hardship and adaptation among Asian American families. Journal of Family Issues, 31, 407-420.

Iwamoto, D., \& Liu, W. (2010). The impact of racial identity, ethnic identity, Asian values, and race-related stress on Asian Americans and Asian international college students' psychological well-being. Journal of Counseling Psychology, 57, 79-91.

Juang, L. P., \& Cookston, J. T. (2009). Acculturation, discrimination, and depressive symptoms among Chinese American adolescents: A longitudinal study. The Journal of Primary Prevention, 30, 475-496.

Juang, L. P., Nguyen, H. H., \& Lin, Y. (2006). The ethnic identity, other-group attitudes, and psychosocial functioning of Asian American emerging adults from two contexts. Journal of Adolescent Research, 21(5), 542-568. 
Kiang, L., Yip, T., Gonzales-Backen, M., Witkow, M., \& Fuligni, A. J. (2006). Ethnic identity and the daily psychological well-being of adolescents from Mexican and Chinese backgrounds. Child Development, 77, 1338-1350.

Lee, R. M. (2003). Do ethnic identity and other-group orientation protect against discrimination for Asian Americans? Journal of Counseling Psychology, 50, 133-141.

Lee, R. M. (2005). Resilience against discrimination: Ethnic identity and other-group orientation as protective factors for Korean Americans. Journal of Counseling Psychology, 52, 36-44.

Lee, S. J. (2001). More than 'model minorities' or 'delinquents': A look at Hmong American high school students. Harvard Educational Review, 71, 505-528.

Lueck, K., \& Wilson, M. (2010). Acculturative stress in Asian immigrants: The impact of social and linguistic factors. International Journal of Intercultural Relations, 34, 47-57. doi:10.1016/j.ijintrel.2009.10.004

Mistry, R. S., Benner, A. D., Tan, C. S., \& Kim, S. (2009). Family economic stress and academic well-being among Chinese-American youth: The influence of adolescents' perceptions of economic strain. Journal of Family Psychology, 23, 279-290.

Oyserman, D., \& Sakamoto, I. (1997). Being Asian American: Identity, cultural constructs, and stereotype perception. Journal of Applied Behavioral Science, 33, 435-453.

Pascoe, E. A., \& Smart Richman, L. (2009). Perceived discrimination and health: A metaanalytic review. Psychological Bulletin, 135, 531-554.

Pew Research Center. (2012). The rise of Asian Americans. Retrieved from http://www.pewsocialtrends.org/2012/06/19/the-rise-of-asianamericans/

Phinney, J. S. (1992). The Multigroup Ethnic Identity Measure: A new scale for use with diverse groups. Journal of Adolescent Research, 7, 156-176.

Phinney, J. S., \& Ong, A. D. (2007a). Conceptualization and measurement of ethnic identity: Current status and future directions. Journal of Counseling Psychology, 54, 271-281.

Phinney, J. S., \& Ong, A. D. (2007b). Ethnic identity development in immigrant families. In J. E. Lansford, K. Deater-Deckard, \& M. H. Bornstein (Eds.), Immigrant families in contemporary society (pp. 51-68). New York, NY: Guilford Press.

Preacher, K. J., Curran, P. J., \& Bauer, D. J. (2006). Computational tools for probing interactions in multiple linear regression, multilevel modeling, and latent curve analysis. Journal of Educational \& Behavioral Statistics, 31, 437-448. 
Rivas-Drake, D., Hughes, D., \& Way, N. (2008). A closer look at peer discrimination, ethnic identity, and psychological well-being among urban Chinese American sixth graders. Journal of Youth and Adolescence, 37, 12-21.

Rosenberg, M. (1989). Society and the Adolescent Self-Image. Rev. ed. Middletown, CT: Wesleyan University Press.

Rosenbloom, S. R., \& Way, N. (2004). Experiences of discrimination among African American, Asian American, and Latino adolescents in an urban high school. Youth \& Society, 35, 420-451.

Rumbaut, R. G. (1994). The crucible within: Ethnic identity, self-esteem, and segmented assimilation among children of immigrants. International Migration Review, 28, 748-794.

Schwartz, S. J., Zamboanga, B. L., \& Jarvis, L. (2007). Ethnic identity and acculturation in Hispanic early adolescents: Mediated relationships to academic grades, prosocial behaviors, and externalizing symptoms. Cultural Diversity \& Ethnic Minority Psychology, 13(4), 364-373. doi: 10.1037/1099-9809.13.4.364

Shelton, J. N., Yip, T., Eccles, J., Chatman, C. M., Fuligni, A. J., \& Wong, C. (2005). Ethnic identity as a buffer in psychological adjustment. In G. Downey, J. Eccles, \& C. M. Chatman (Eds.), Navigating the future: Social identity, coping and life tasks (pp. 96-115). New York, NY: Russell Sage Foundation.

Stamps, K., \& Bohon, S. A. (2006). Educational attainment in new and established latino metropolitan destinations. Social Science Quarterly, 87, 1225-1240.

Supple, A. J., McCoy, S. Z., \& Wang, Y. C. (2010). Parental influences on Hmong university students’ success. Hmong Studies Journal, 11, 1-37.

Tajfel, H., \& Forgas, J. P. (2000). Social categorization: Cognitions, values, and groups. In C. Stangor (Ed.), Stereotypes and prejudice: Essential readings (pp. 49-63). New York, NY: Psychology Press.

Umaña-Taylor, A. J., \& Shin, N. (2007). An examination of ethnic identity and self-esteem with diverse populations: Exploring variation by ethnicity and geography. Cultural Diversity \& Ethnic Minority Psychology, 13, 178-186.

U.S. Census Bureau. (2009). Income, poverty, and health insurance in the United States: 2009 tables and figures. Retrieved from http://www.census.gov/econ/census09/ 